\title{
The effects of new firm formation on regional development over time: The case of Great Britain
}

\author{
Pamela Mueller · André van Stel · David J. Storey
}

Received: 19 December 2005/ Accepted: 20 March 2007/Published online: 26 May 2007

(C) Springer Science+Business Media B.V. 2007

\begin{abstract}
This paper re-examines the link between new firm formation and subsequent employment growth. It investigates whether it is possible to have the wrong type of entrepreneurship-defined as new firm formation which leads to zero or even negative subsequent employment growth. It uses a very similar approach to that of Fritsch and Mueller (Regional Studies, 38(8), 961-976, 2004), confirming their findings that the employment impact of new firm formation is in three discrete phases. Then, using data for Great Britain, the paper shows the employment impact of new firm formation is significantly positive in the high-enterprise counties of Great Britain.
\end{abstract}

P. Mueller ( ()

Max Planck Institute of Economics, Kahlaische Strasse 10, 07745 Jena, Germany

e-mail: pmueller@econ.mpg.de

A. van Stel · D. J. Storey

EIM Business and Policy Research, Zoetermeer, The Netherlands

A. van Stel

Cranfield University School of Management, Cranfield, UK

A. van Stel

Max Planck Institute of Economics, Jena, Germany

D. J. Storey

Centre for Small and Medium Sized Enterprises,

University of Warwick, Coventry, UK
However, for the low-enterprise counties, it shows that new firm formation has a negative effect on employment. Of the 15 low-enterprise regions, eight are Scottish (of nine Scottish regions in our data base) and three are North East Counties (of four). Our findings imply that having the "wrong type of entrepreneurship" is indeed possible.

Keywords New firm formation - Employment growth · Great Britain - Low-entrepreneurial regions

JEL classifications $\quad \mathrm{J} 23 \cdot \mathrm{L} 10 \cdot \mathrm{M} 13 \cdot \mathrm{R} 11 \cdot \mathrm{L} 26$

\section{Introduction}

This paper re-examines a familiar topic-the link between new firm formation and subsequent employment growth. Its novelty is to pose the almost heretical question of whether it is possible to have "the wrong type of entrepreneurship" - defined as new firm formation which leads to zero or even negative subsequent employment growth.

The importance of the question is reflected in the efforts of public policy makers throughout the world to seek to raise new firm formation on the grounds that this will lead to additional employment. In principle it is clear that if a new firm is created and it employs, either as an owner or as an employee, an individual who was formerly not employed, then this adds to aggregate employment in the economy. 
This paper, however, makes it clear that additional employment resulting from new firm formation activity is achieved only when certain key assumptions are made. The first is that it is possible for policy makers to take actions, which stimulate new firm formation. Second, that it is the policy, and not macro economic circumstances, that cause the change.

A third and very important assumption is that it is new firm formation which causes increased employment and not vice versa, since increased employment may be the cause rather than the consequence of higher start-up rates. This is because local demand is likely to be higher when employment increases, so stimulating the creation of new firms. As these two mechanisms differ greatly in their policy implications, it is of vital importance to disentangle the correct direction of causality.

The final, and key, assumption is that not only is the immediate employment impact quantified, but also any subsequent employment change attributable to the new firm. In order to address this issue we utilise the framework formulated by Fritsch and Mueller (2004). They show the creation of a new firm has both immediate and longer-term consequences. As noted above, new firms have an easily identifiable short-term direct effect in creating employment, but they also have two longer-term consequences. The first is that new firms displace inefficient incumbents, which may lead to job losses in the medium term. A second medium term consequence is that the new firms grow themselves and also enhance the competitiveness of firms that remain in business, ${ }^{1}$ acting as a threat to incumbent firms inducing improved performance from them. As Fritsch and Mueller (2004) show, the effect of new entrants is therefore threefold: the first effect is to increase employment, the second is to lower employment and the third is to increase employment. The total effect upon employment can therefore be either positive or negative and depends upon the magnitude of the three elements.

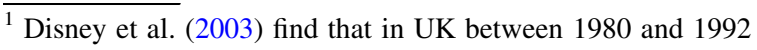
about half of productivity gain was because of internal factors-such as introducing new technology and organisational changes. The remaining half was because of external factors most notably that the entrants were more productive than those exiting. However amongst single plant independent firms almost all the gains were attributable to external factors.
}

This paper applies the Fritsch and Mueller (2004) approach to data for Great Britain in order to examine our central question of whether some entrepreneurship is "better' than others. Given that those countries and/or regions with both low rates of new firm formation and low-employment levels are most likely to implement such policies, this paper asks whether the short, medium and long-term job creation effects of new firm formation differ between areas. Specifically, do new firms started in low-entrepreneurship areas have a weaker job creation impact than those started in high-entrepreneurship areas?

To test this, the paper examines the effects of new firm formation on subsequent employment change between 1981 and 2003 for Great Britain. It makes two distinctions. The first is between England on the one hand and Scotland and Wales on the other. This is because the policy regime was different, particularly in Scotland, during the period in question. A second distinction is made by pooling all geographical areas in the three countries, ranking them on the basis of new firm formation, and then comparing the bottom quartile areas with the other areas.

Our broad key finding is that, for Great Britain as a whole and England in particular, the effect of new firm formation on subsequent employment growth is positive. Hence new firm formation led subsequently to increased employment in that country during this period. However, we do not get the same results for Scotland and Wales, nor for the lower quartile regions, none of which are located in East Anglia, the Midlands or the South of England. For Scotland and Wales the overall impact of new firm formation is considerably smaller compared to England. For the lower quartile regions of Great Britain as a whole (mainly regions in Scotland and the North East of England) the effect is negative, implying that the aggregate long-term impact of new firm formationand the impact of policies to raise new firm formation-may be negative. Our final section discusses the possible regionally regressive implications of entrepreneurship policy.

The paper begins with a brief review of the original Fritsch and Mueller (2004) model, primarily to provide an understanding of the circumstances under which the employment consequences of entrepreneurship can be either positive, zero or negative. It 


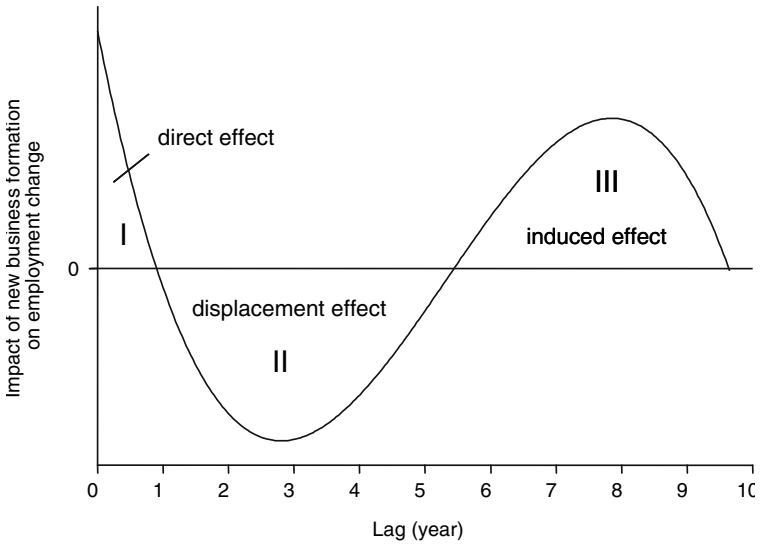

Fig. 1 Schematic effects of new firm formation on employment change (according to Fritsch and Mueller 2004)

then turns to examine the policy context in Great Britain over the last two decades in which the emphasis upon new firm formation has fluctuated markedly. The data are set out in Sect. 5, the analysis in Sect. 6 with our interpretation of the implications in Sect. 7.

\section{Literature overview}

Fritsch and Mueller's (2004) work on Germany provided both a model and a test of time lags in the relationship between new firm formation and employment change. They theorised that new firm formation had three effects, which are shown in Fig. 1. The first effect was a short-term direct effect of employment created by the new firm. The second was the displacement effect of the entrant causing existing firms to go out of business, hence incurring job losses. Finally, the third effect is to stimulate better performance from surviving firms. This is called the induced effect.

Applying this theory to German data Fritsch and Mueller (2004) find support for the three phase model. They concluded that the peak of positive impact of new firms on regional economic development was reached about 8 years after entry, and disappeared after about a decade. Using a broadly similar approach, van Stel and Storey (2004) examined Great Britain for the period 1981-1998. Their conclusions were similar to those of Fritsch and Mueller (2004). They found the employment impact of new firm formation was maximised after 5 years but had declined to zero by year $9 .^{2}$

In the context of the current paper, the important finding of van Stel and Storey (2004) is that in 'unentrepreneurial areas', such as North-East England and Scotland, the employment effect was not consistently positive. Figure 1 provides a good context for understanding these matters. Assume two regions A and $\mathrm{B}$. Region $\mathrm{A}$ is prosperous and has high rates of new firm formation. Region B is the reverse. In principle, for the employment consequences of new firm formation in the two regions to differ then the case has to be made for some or all of the following: lower Phase-I employment, higher Phase-II and/or lower Phase-III employment.

Our case is that the employment consequences of public policies intended to raise new firm formation would be lower in the low income, low-enterprise areas. Our assumption is that areas of low enterprise-Region B-have the documented characteristics of Tees Valley in Northern England (Greene et al. 2004): individuals with low levels of education, low levels of home ownership, low-house prices, low inmigration, high unemployment, a high proportion of manufacturing employment, heavily concentrated in large plants, low levels of research and development and low proportions of business service employment. Our second assumption is that public policies to raise new firm formation rates are implemented. We now speculate on the expected differential impact of these policies in Regions A and B.

\subsection{Phase I}

New firms started by individuals in Region B are likely to be smaller in Phase I than those in Region A. This is because such individuals have less wealth since they are both less likely to own a property than those in Region A and that property is of lower value. They also have less borrowing power than those in Region A because of lower educational qualifications and poorer business prospects because, since most small firms sell locally, market conditions are likely to be less buoyant. New firms in Region B are more likely to be started in

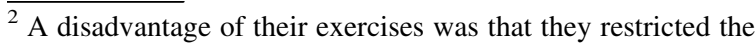
Almon lag polynomial to be of second degree while Fritsch and Mueller showed that a third degree polynomial may actually be more realistic.
} 
sectors with low-entry barriers such as personal services $^{3}$ where capital requirements are modest and skills and expertise are widely available. The only advantage that businesses in Region B may have is in being able to access public support such as finance and advice, which is less likely to be available in Region A.

\subsection{Phase II}

If new firms started by individuals in Region B are both financed initially from public funds and heavily concentrated in low-skill personal services, then their short-term effect will be to displace existing providers of such services on grounds of price. There will therefore be a bigger negative impact in Phase II in Region B than Region A where both the firms are "better" and do not receive a temporary subsidy.

\subsection{Phase III}

In this phase the employment created reflects the growth in both the new firms and those whose performance has been enhanced as a result of the competition provided by the entrants. Here again the case is that the employment growth of firms in this phase will be lower in Region B than in Region A. This reflects the lower levels of entrepreneurial expertise of the owners of firms in Region B and the less buoyant market conditions in that region.

Overall therefore Fig. 1 shows that there are three phases of employment creation associated with new firm formation and that whilst Phase I would be expected to be positive, the inclusion of Phases II and III makes this more ambiguous. Second, we argue that the magnitude of the employment created in each phase is different in prosperous compared with less prosperous regions. Third, we argue that policies to raise new firm formation in areas with low rates could lead to zero or even negative net employment creation over the three phases. A brief overview of the policy context in Great Britain is now provided.

\section{Policy context}

Greene et al. (2004) identify four separate SME/ Enterprise policy periods. The first is the 1970s when

\footnotetext{
3 Examples include hairdressing, beauticians, taxi driving, deliveries, window cleaners, car repairs, etc.
}

GB enterprise policy-defined as providing assistance and support for new and small firms-hardly existed. The 1970s is therefore viewed as a "policy off' "period.

The arrival of Margaret Thatcher as Prime Minister in 1979 changed matters radically. She saw enterprise creation as highly desirable in itself, but also as a direct mechanism for lowering unemployment levels. The 1980s can therefore be considered as a decade characterised by support for new start-up businesses.

The 1990s saw a shift in this policy, away from new firms and towards providing support for existing small firms with growth potential (for reasons underlying this shift, see Greene et al. 2004). For GB as a whole therefore, the mid to late 1990s sees considerably less emphasis placed by policy makers upon new firms. The 1990s can therefore be viewed as a decade in which the focus was on smaller firms with growth potential. Finally, following the election of a Labour government in 1997, the decade of 2000 sees a further change, with policies being focussed more specifically on seeking to enhance productivity and increase social inclusion. In this period, both some types of new firms and some types of growing firms are supported. ${ }^{4}$

Whilst these policies were being implemented in Great Britain-and specifically in England-different policies were being adopted in Scotland in the 1990s, and Wales from 2001. ${ }^{5}$ At a time when English policies focussed upon growth businesses, Scottish policy makers became concerned that their new firm formation was much lower than that of England. To address this, Scotland launched its Business Birth Rate Policy in 1993. This programme cost $£ 140 \mathrm{~m}$ over the period until 2002. Its task was to close the gap between new firm formation rates in Scotland and those of the rest of

\footnotetext{
$\overline{4}$ These policies were formalised in Small Business Service (2004). This identified the so-called seven pillars: building an enterprise culture, encouraging a dynamic start up market, building the capability for small business growth, improving access to finance for small businesses, encouraging more enterprise in disadvantaged communities and under-represented groups, improving small businesses' experience of government services and developing better regulation and policy.

5 Northern Ireland is excluded from this review because, although it also had active and independent enterprise policies and so would have been of real interest, the data available does not cover Northern Ireland.
} 
UK by the end of the 1990s. In 2001 the policy was reviewed ${ }^{6}$ and it was concluded that it had failed to reach its main target, although there had been a "small but systematic increase in the Scottish business birth rate'. Following the review an overhaul took place, with policy being less explicitly focussed on raising new firm formation. As Scotland was reviewing its business birth rate strategy in 2001, Wales was introducing its Entrepreneurial Action Plan (EAP), one component of which was to seek to raise the business birth rate in that country.

In short, GB enterprise policy has changed on a number of occasions over the past two decades, with the 1980s being the decade in which it was most explicitly focussed on raising new firm formation. However Scotland in the 1990s and Wales after 2001 both sought to raise aggregate formation rates at a time when England was placing less emphasis upon this approach.

\section{Data sources}

The basic data on new firm formation are shown in Fig. 2. It shows that over the period 1980-2003, new firm formation rates-measured as new VAT Registrations $^{7}$ per 10,000 inhabitants-are consistently lower in Wales and Scotland than in England. The overall rate of Great Britain is very close to the England rate because England is the numerically dominant country. On average about $90 \%$ of the VAT registration in Great Britain take place in England. Wales counts for only about $4 \%$ of the registrations

\footnotetext{
${ }^{6}$ Fraser of Allander 2001.

${ }^{7}$ All businesses, other than those in exempt sectors, above a minimum sales threshold of $£ 61,000$ (April 2006) are required to be registered for VAT. Official statistics on new businesses are based on firms newly registering with Revenue and Customs. The limitation of VAT data for our purposes is partly the exemptions but more the nature of the sales threshold. Given that many businesses will have annual sales of less than $£ 61,000$ there will be undercounting. But, more important in our context, this undercounting is likely to be regionally biased. This is because low-enterprise areas are likely to have lower prices of inputs and sales than in more prosperous areas for the reasons outlined in Sect. 2. However, VAT registrations are the basis for official statistics and have the key advantage of being available at a disaggregated level since 1980. Whilst far from ideal, they are the best currently available.
}

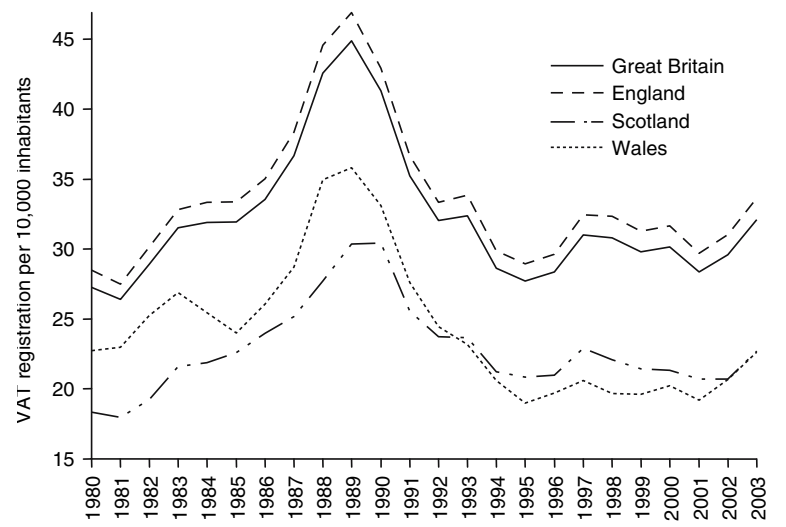

Fig. 2 VAT Registration per 10,000 inhabitants, 1980-2003

and Scotland consequently for $6 \%$. Figure 2 also shows that there is a similar pattern over time in England, Scotland and Wales, with new firm formation rates rising in all three countries at least until 1989, then falling until 1994-1995 and subsequently being broadly stable. Hence, although the new firm formation rates fluctuated over time, the distribution between the three countries is very constant over the period 1980-2003. Finally, there is some support for policy impact at GB level during the 1980s. This was the decade in which Thatcher policies focussed upon stimulating new firm formation, and it is also the decade in which formation rates are highest in all three countries. ${ }^{8}$

The data on employment used is taken from the Census of Employment and, from 1995 onwards, the Annual Employment Survey. Data are supplied by Nomis with the self-employed and unpaid family workers being excluded from the data. In examining the lagged relationship between new firm formation and employment we need to control for factors such as hourly wages and population density. Wage data are derived from the New Earnings Survey Panel (NESP) Dataset and were converted into constant prices in 2003. Data on population density were taken from the Office for National Statistics.

The unit of analysis is 60 British regions-46 English Counties, 4 Welsh Regions and 10 Scottish Local Authority Regions over the period 1981-2003. Because of missing (employment) data, the region

\footnotetext{
$\overline{{ }^{8} \text { Our purpose }}$ here is not to provide a review of the issues relating to new firm formation at a regional level in UK. The reader interested in this topic is advised to consult AnyadikeDanes et al. (2005) or Johnson (2005).
} 
Orkney/Shetland/Western Isles had to be excluded, therefore generating 59 observations. As noted earlier, Northern Ireland could not be included in the analysis because of missing data. Different regional and sectoral classifications in the original data files meant some linking operations were performed to ensure uniformity for 1980-2003 (see Van Stel and Storey 2004 for details). The agricultural sector (also including forestry and fishing) is excluded as it is fundamentally different from the rest of the economy having, during this period, exceptionally low start-up and death rates.

\section{Data analysis}

The regions in England and the regions in Scotland and Wales show the same pattern regarding the correlation of new firm formation over time (Fig. 3). There is a strong correlation in the short-term between start-up rates, but this correlation weakens over time. Second, there is a strong variation over space, with some regions having only four start-ups per 1,000 employees and others more than 15 new businesses per 1,000 employees. English regions generally have higher start-up rates than those in Wales or Scotland.

Figure 3 plots the correlation of new firm formation for two time periods. The first is the relationship between start-ups in $t$ and in $t-1$ and the second is between $t$ and $t-5$. A distinction is made between England on the one hand (Fig. 3a) and Scotland and Wales on the other (Fig. 3b).

Table 1 shows the persistency of new firm formation over time at the regional level. The startup rate in period $t$ heavily depends on the start-up rate in the previous year and is also significantly determined by new firm formation activity five, ten and 15 years previously. The beta-coefficients indicate the strong pattern of path dependency, which weakens over time. More than $80 \%$ of the variation of the start-up rate in $t$ can be explained by new firm formation activity $1,5,10$ and 15 years previously.

\section{Formally modelling the time lags}

To formally address the issue of time-lags, the first step is to estimate a model relating employment change over a 2-year period (between $t$ and $t+2$ ) to start-up rates in year $t$ and each of the preceding 8 years.

\subsection{Great Britain}

The results for Great Britain as a whole are shown in Table 2. We also include measures of population density, wages, lagged employment change ${ }^{9}$ and a term to address spatial auto correlation (see, e.g. Keeble et al. 1993 or Anselin 1988). The results are also illustrated graphically in Fig. 4. The smoothed line obtained in Fig. 4 is drawn on the basis of the socalled restricted parameters in Table 2. These restrictions are necessary because the initial regression suffers from multicollinearity caused by the high correlations over time of the start-up rates (see Table 1). These problems of multicollinearity are avoided using the Almon lag method ${ }^{10}$. Basically this method imposes restrictions on the parameters of the start-up rates in such a way that the estimated coefficients of the start-up rates are a function of the lag length. Substituting these restrictions back in the original equation produces a more compact model that overcomes the problems of multicollinearity.

It is clear from Table 2, using both a fixed effects model and a Huber-White Robust Model, that there are three different impacts. ${ }^{11}$ The initial effect is positive in year $t$ but becomes negative in $t-1$ and is significantly negative in $t-3$. Both models show that, in year $t-6$, effects become significantly positive. Graphically this may be seen by comparing the areas under and above the horizontal line. The area below the horizontal line in Fig. 4 can be considered as the negative employment effects of new firm formation. The positive effects are shown above the horizontal line-the period of up to year 1 and the period from year 4 to year 8 . The net effects which are positive for Great Britain are clearly shown in Fig. 4 and strong evidence that the

\footnotetext{
${ }^{9}$ This variable is included to control for the reversed causality issue discussed in the introduction (see also Granger 1969).

${ }^{10}$ Stewart (1991, pp 180-182) provides a general description of the Almon method.

${ }^{11}$ As the fixed effects method effectively considers the effects over time only, and the purpose of our paper is to explicitly examine the short and long run effects over time, we mainly focus on the fixed effects results in our discussion. However, the Huber White results are useful for robustness test purposes.
} 

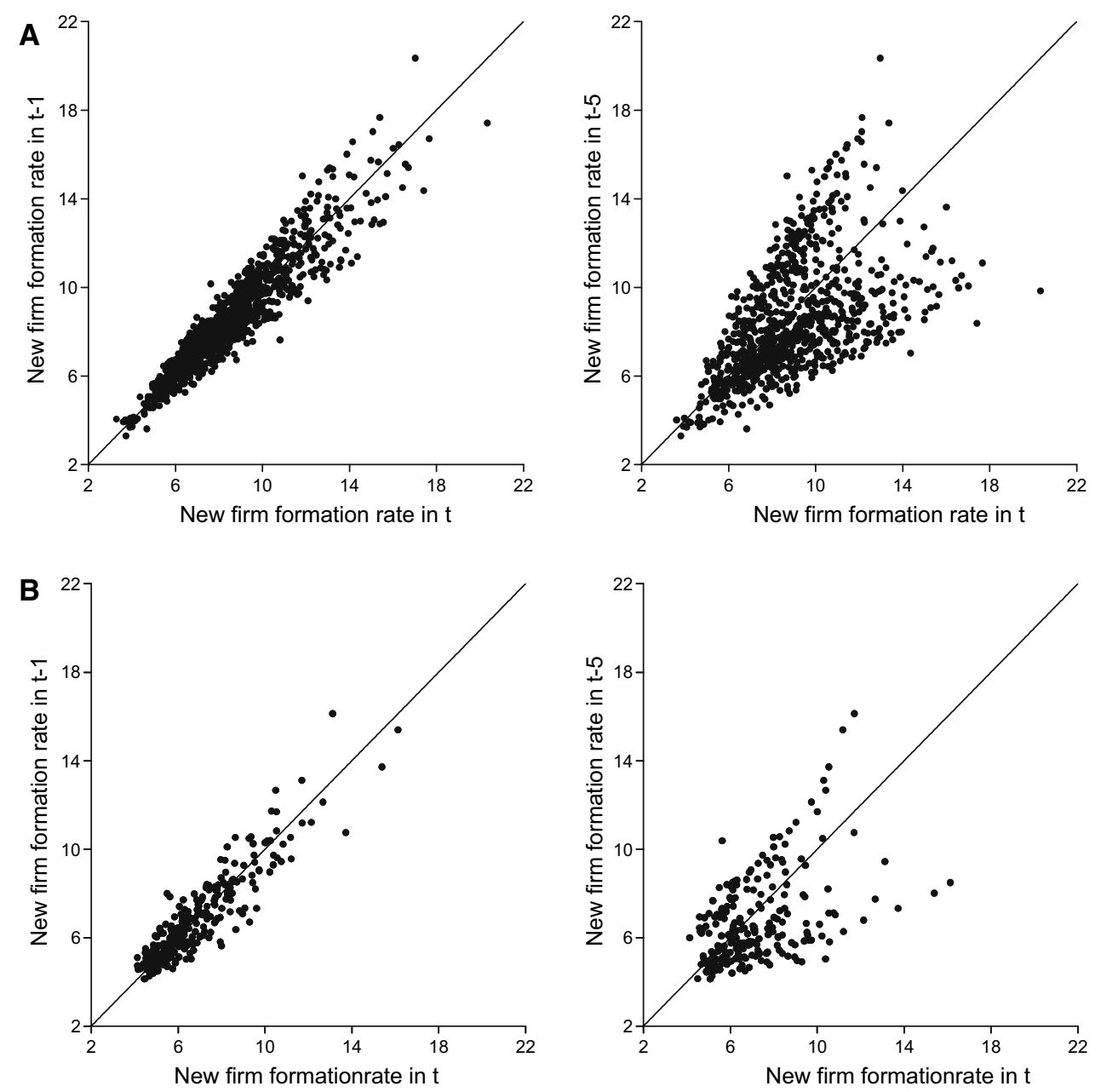

Fig. 3 (a) Correlation of new firm formation rates over time in England (start-ups per 1,000 employees). (b) Correlation of new firm formation rates over time in Wales and Scotland (start-ups per 1,000 employees)

Mueller Fritsch model for Germany is also valid for Great Britain. ${ }^{12}$

The signs on the control variables imply a positive effect of hourly wages ${ }^{13}$ and spatial autocorrelation, and negative effects of lagged employment growth

\footnotetext{
${ }^{12}$ One of our anonymous referees wondered whether this was a GB effect or simply a London effect. We re-ran the equations and found that the exclusion of London had only a very marginal effect on the coefficients and their significance.

${ }^{13}$ This might be thought to be a counter intuitive finding since self employment theory (Parker 2004) would imply that individuals would move into self employment-business ownership-when wages fall. On those grounds high wage regions might be expected to have low rates of new firm formation. Our view is that this is only the case ceteris paribus. Of greater significance are the other factors working in a contrary direction such as access to finance and local demand.
}

(indicating business cycle effects) and population density. This last variable is meant to control for regional characteristics such as housing prices, qualified labour, local demand, and knowledge. Note that the coefficient is not significant using the fixed effect estimator since regional differences, which are timepersistent (such as population density) are already accounted for in the fixed effect. ${ }^{14}$

\footnotetext{
${ }^{14}$ When using fixed effects we realise that inclusion of a lagged dependent variable might lead to a bias in the estimation results. However, comparing the coefficient for the lagged dependent of the FE regression with that of the Huber White regression we see that these are very similar. Therefore, we argue that this bias is, at the most, small. Because the effect of the lagged dependent is very significant we choose to include it in our model, despite the disadvantage mentioned.
} 


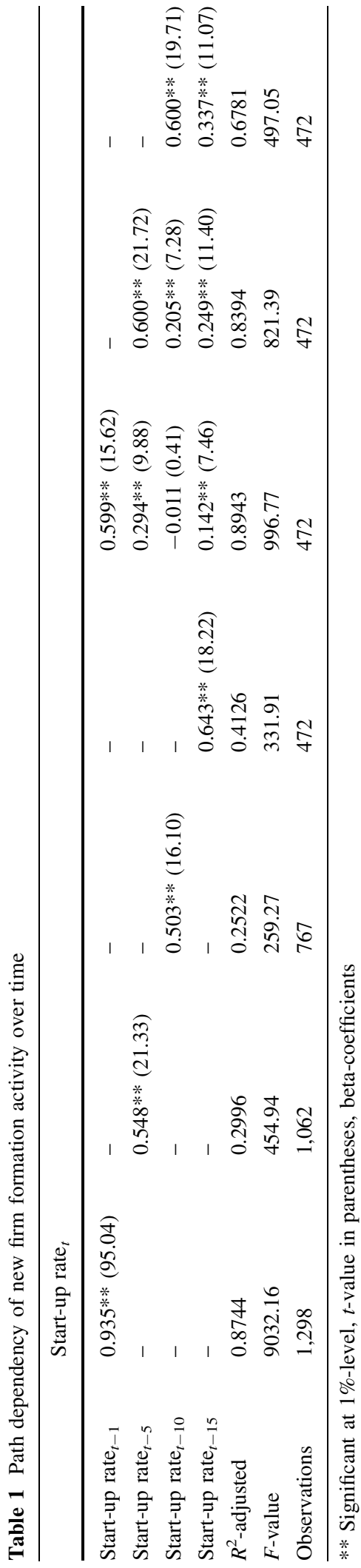

6.2 Comparing England with Wales and Scotland

Table 3 makes this comparison. It begins by presenting the results for England, followed by those for Scotland and finally for Wales. It uses an interaction dummy to indicate new firm formation rates in England compared with Scotland and Wales. The results are plotted in Fig. 5.

Unsurprisingly given its size dominance, the results for England are very similar to the earlier results for Great Britain. Most importantly, in England, the net impact of new firm formation on employment is positive. In particular, the impact of Phase III-the competitiveness phase-is larger than for Phase II-the displacement phase.

Most importantly we find a striking difference between the results for England and Scotland (Table 3). Although the basic pattern of three phases is the same, Scotland shows almost no employment gain in the competitiveness phase. Instead it is characterised by a relatively larger Phase I and a longer negative Phase II. ${ }^{15}$ This implies that the characteristics of new firms in Scotland do differ sharply from those in England. Wales experiences a stronger crowding out effect and a lower induced effect compared with England. Nevertheless, the employment effects over time in Wales are very similar to the effects in England.

The results point to clear differences between England and Scotland, but much smaller differences between England and Wales. In order to test if these differences are significant we carry out a likelihood ratio test (LR test) comparing the models including the interaction dummies from Table 3 with the general

\footnotetext{
$\overline{15}$ We should be careful when interpreting the large positive Phase I for Scotland. Using data for The Netherlands, van Stel and Suddle (2007) demonstrate that there is a danger of overestimating the direct effect when applying the Almon method. This is due to reversed causality effects.
} 
Table 2 Long-term effects of new firm formation activity on employment change: Great Britain

\begin{tabular}{|c|c|c|c|c|}
\hline & \multicolumn{4}{|c|}{ 2-Year regional employment change $(\%)$} \\
\hline & \multicolumn{2}{|c|}{ Fixed effect estimator } & \multicolumn{2}{|c|}{ OLS estimator (Huber White) } \\
\hline & Un-restricted & Third-order polynomial & Un-restricted & Third-order polynomial \\
\hline Start-up rate $(t)$ & $0.881 * *(3.81)$ & 0.828 & $0.732 * *(4.36)$ & 0.678 \\
\hline Start-up rate $(t-1)$ & $-0.492(1.78)$ & -0.205 & $-0.529 * *(2.78)$ & -0.267 \\
\hline Start-up rate $(t-2)$ & $0.027(0.10)$ & -0.569 & $-0.083(0.48)$ & -0.576 \\
\hline Start-up rate $(t-3)$ & $-0.878 * *(3.24)$ & -0.468 & $-0.823 * *(3.73)$ & -0.451 \\
\hline Start-up rate $(t-4)$ & $-0.206(0.75)$ & -0.111 & $-0.141(0.54)$ & -0.089 \\
\hline Start-up rate $(t-5)$ & $0.508(1.83)$ & 0.297 & $0.499(1.82)$ & 0.308 \\
\hline Start-up rate $(t-6)$ & $0.732 * *(2.66)$ & 0.549 & $0.729 * *(2.82)$ & 0.542 \\
\hline Start-up rate $(t-7)$ & $-0.026(0.10)$ & 0.440 & $-0.105(0.46)$ & 0.412 \\
\hline Start-up rate $(t-8)$ & $0.041(0.22)$ & -0.238 & $0.009(0.05)$ & -0.281 \\
\hline Population density & $0.005(0.54)$ & $0.006(0.60)$ & $-0.001 * *(4.37)$ & $-0.001 * *(4.37)$ \\
\hline Hourly wages (constant prices) & $1.108 * *(2.64)$ & $1.072 * *(2.57)$ & $0.546^{* *}(3.51)$ & $0.558 * *(3.74)$ \\
\hline 2-Year employment change $(t-2)$ & $-0.333 * *(9.35)$ & $-0.326 * *(9.44)$ & $-0.259 * *(5.88)$ & $-0.257 * *(5.99)$ \\
\hline Spatial autocorrelation & $0.590 * *(8.88)$ & $0.568 * *(8.54)$ & $0.542 * *(6.62)$ & $0.524 * *(6.54)$ \\
\hline Constant & $14.257 *(2.12)$ & $-13.716^{*}(2.04)$ & $-3.700 * *(3.18)$ & $-3.725 * *(3.28)$ \\
\hline$R^{2}$-adjusted & 0.2946 & 0.2899 & 0.3167 & 0.3138 \\
\hline F-Value & 30.07 & 47.33 & 21.00 & 33.27 \\
\hline Log-likelihood & $-2,059.80$ & $-2,065.11$ & $-2,098.85$ & $-2,102.97$ \\
\hline Observations & 767 & 767 & 767 & 767 \\
\hline
\end{tabular}

* Significant at 5\%-level

** Significant at $1 \%$-level

$t$-values in parentheses

model from Table $2 .{ }^{16} \mathrm{We}$ conclude that the difference in impact between England on the one hand and Scotland and Wales on the other is statistically significant.

\footnotetext{
$\overline{16}$ There are two cases. First, there are the basic (unrestricted) estimations. In terms of the LR test the log likelihood value for the unrestricted model is $(2,043.19$ and that of the restricted model (i.e. 'restricting' the effects of England, Scotland and Wales to be the same) $(2,059.80$. The corresponding LR test statistic thus equals 33.22. The critical value of the chi-squared distribution with 18 degrees of freedom (there are 18 restrictions corresponding to the 18 interaction dummies) is 28.87 at the $5 \%$ significance level. Hence the null hypothesis of valid restrictions is rejected. Second, there are the restricted (thirdorder polynomial) estimations. Here the test statistic amounts to a value of 22.06 and the critical value is 15.51 since there are eight restrictions corresponding to the eight additional polynomial terms for Scotland and Wales. Again, the null hypothesis is rejected.
}

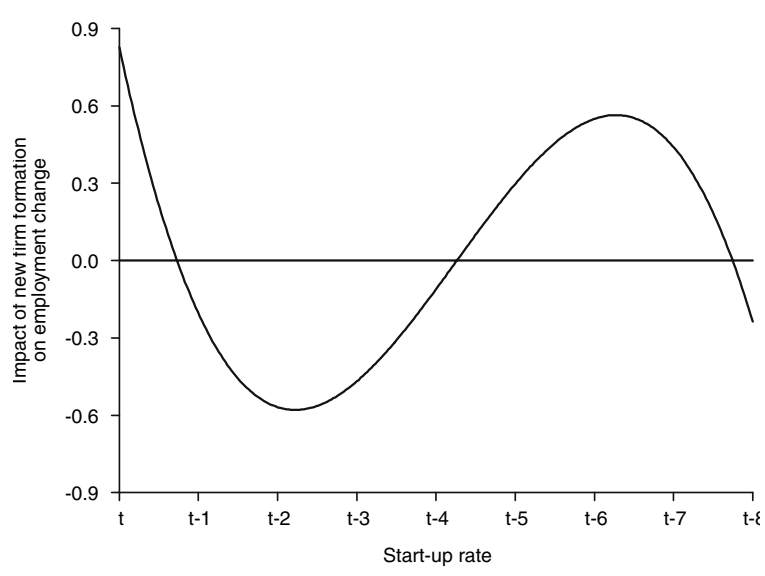

Fig. 4 Impact of new firm formation on employment change for GB regions (fixed effects estimator)

\subsection{Comparing low- and high-entrepreneurial areas}

The above analysis showed the characteristics of new firms in Wales and Scotland differ from those in 
Table 3 Long-term effects of new firm formation activity on employment change-England versus Scotland versus Wales

\begin{tabular}{|c|c|c|c|c|}
\hline & \multicolumn{4}{|c|}{2 -Year regional employment change $(\%)$} \\
\hline & \multicolumn{2}{|c|}{ Fixed effects estimator } & \multicolumn{2}{|c|}{ OLS estimator (Huber White) } \\
\hline & Un-restricted & Third-order polynomial & Un-restricted & Third-order polynomial \\
\hline \multicolumn{5}{|l|}{ England } \\
\hline Start-up rate $(t)$ & $0.954 * *(3.69)$ & 0.851 & $0.639 * *(3.32)$ & 0.600 \\
\hline Start-up rate $(t-1)$ & $-0.560(1.77)$ & -0.184 & $-0.575 * *(2.78)$ & -0.307 \\
\hline Start-up rate $(t-2)$ & $-0.031(0.10)$ & -0.552 & $-0.192(1.00)$ & -0.589 \\
\hline Start-up rate $(t-3)$ & $-0.601 *(1.94)$ & -0.456 & $-0.536 *(2.36)$ & -0.444 \\
\hline Start-up rate $(t-4)$ & $-0.308(0.98)$ & -0.097 & $-0.264(0.97)$ & -0.070 \\
\hline Start-up rate $(t-5)$ & $0.357(1.12)$ & 0.322 & $0.364(1.43)$ & 0.336 \\
\hline Start-up rate $(t-6)$ & $0.839 * *(2.59)$ & 0.597 & $0.796 * *(2.84)$ & 0.575 \\
\hline Start-up rate $(t-7)$ & $0.358(1.13)$ & 0.529 & $0.291(1.08)$ & 0.449 \\
\hline Start-up rate $(t-8)$ & $-0.073(0.34)$ & -0.087 & $-0.211(1.15)$ & -0.239 \\
\hline \multicolumn{5}{|l|}{ Wales } \\
\hline Start-up rate $(t)$ & $1.270(1.39)$ & 0.966 & $1.556(1.86)$ & 0.928 \\
\hline Start-up rate $(t-1)$ & $-0.808(0.74)$ & -0.298 & $-0.859(0.89)$ & -0.199 \\
\hline Start-up rate $(t-2)$ & $0.031(0.03)$ & -0.726 & $-0.210(0.40)$ & -0.605 \\
\hline Start-up rate $(t-3)$ & $-1.106(1.06)$ & -0.589 & $-0.997(1.17)$ & -0.513 \\
\hline Start-up rate $(t-4)$ & $-0.448(0.41)$ & -0.157 & $0.370(0.79)$ & -0.145 \\
\hline Start-up rate $(t-5)$ & $0.781(0.66)$ & 0.299 & $1.117(1.21)$ & 0.276 \\
\hline Start-up rate $(t-6)$ & $1.273(1.12)$ & 0.510 & $1.042(1.53)$ & 0.528 \\
\hline Start-up rate $(t-7)$ & $-1.524 *(1.46)$ & 0.205 & $-1.804(1.51)$ & 0.388 \\
\hline Start-up rate $(t-8)$ & $0.138(0.20)$ & -0.886 & $0.878(1.35)$ & -0.366 \\
\hline \multicolumn{5}{|l|}{ Scotland } \\
\hline Start-up rate $(t)$ & $1.503 * *(2.73)$ & 1.330 & $1.400 * *(3.38)$ & 1.138 \\
\hline Start-up rate $(t-1)$ & $0.139(0.20)$ & 0.287 & $-0.045(0.08)$ & 0.228 \\
\hline Start-up rate $(t-2)$ & $0.329(0.47)$ & -0.233 & $0.273(0.49)$ & -0.230 \\
\hline Start-up rate $(t-3)$ & $-1.836 * *(2.61)$ & -0.372 & $-1.821 * *(3.29)$ & -0.355 \\
\hline Start-up rate $(t-4)$ & $0.383(0.55)$ & -0.269 & $0.623(0.81)$ & -0.265 \\
\hline Start-up rate $(t-5)$ & $0.830(1.24)$ & -0.065 & $0.656(0.76)$ & -0.079 \\
\hline Start-up rate $(t-6)$ & $0.044(0.07)$ & 0.101 & $0.107(0.20)$ & 0.086 \\
\hline Start-up rate $(t-7)$ & $-1.238^{*}(2.06)$ & 0.088 & $-1.393 *(2.49)$ & 0.111 \\
\hline Start-up rate $(t-8)$ & $0.469(0.86)$ & -0.243 & $0.736(1.85)$ & -0.121 \\
\hline Population density & $0.002(0.17)$ & $0.002(0.22)$ & $-0.001 * *(3.96)$ & $-0.001 * *(4.06)$ \\
\hline Hourly wages (constant prices) & $1.452 * *(3.37)$ & $1.332 * *(3.13)$ & $0.554 * *(3.80)$ & $0.553 * *(3.90)$ \\
\hline 2-Year employment change $(t-2)$ & $-0.339 * *(9.27)$ & $-0.345 * *(9.86)$ & $-0.261 * *(6.05)$ & $-0.272 * *(6.29)$ \\
\hline Spatial autocorrelation & $0.533 * *(7.64)$ & $0.520 * *(7.57)$ & $0.485 * *(4.95)$ & $0.486^{* *}(5.34)$ \\
\hline Constant & $-17.332 *(2.53)$ & $-16.209 *(2.37)$ & $-4.202 * *(3.44)$ & $-4.136 * *(3.42)$ \\
\hline$R^{2}$-adjusted & 0.3065 & 0.3020 & 0.3268 & 0.3227 \\
\hline$F$-value & 13.79 & 25.34 & - & 26.17 \\
\hline Log-likelihood & $-2,043.19$ & $-2,054.08$ & $-2,083.87$ & $-2,093.94$ \\
\hline Observations & 767 & 767 & 767 & 767 \\
\hline
\end{tabular}

* Significant at 5\%-level

** Significant at $1 \%$-level

$t$-values in parentheses 


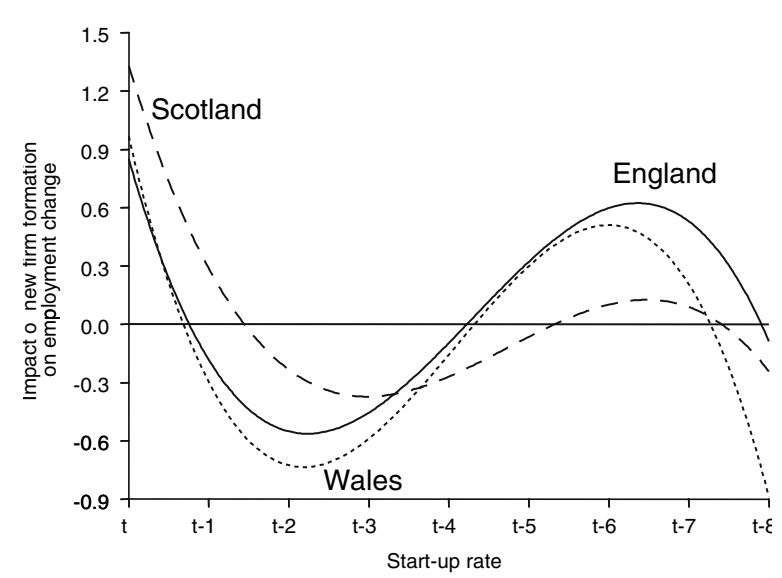

Fig. 5 Impact of new firm formation on employment change-England versus Scotland and Wales (fixed effects estimator)

England. We argued that this is related to the differences in start-up rates, i.e. on average relatively high start-up rates in England and lower rates in Wales and Scotland (see Fig. 2).

Whilst it is valid to distinguish England from Scotland and Wales since they are different countries and they have adopted different enterprise policies at different points in time, all three are part of Great Britain. Of even greater significance from the viewpoint of this paper, it would be incorrect to simply categorise England as having high rates of new firm formation and Wales and Scotland as having low rates. If our purpose is to compare employment in high- and low-new firm formation areas then these have to be more clearly specified.

For this purpose regions are now re-classified as low entrepreneurial if they belong to the lower 25 percentile in terms of their average start-up rate. Fifteen regions are classified as low entrepreneurial. Six of the 15 regions are located in England, three of which are in the North East: Former County of Cleveland, Former County of Durham, Tyne and Wear Metropolitan County, Cumbria County, Merseyside Metropolitan County, South Yorkshire Metropolitan County. West Glamorgan in Wales and 8 Scottish regions (Central, Dumfries and Galloway, Fife, Grampian, Highland, Lothian, Strathclyde and Tayside) are also classified as low entrepreneurial. Although the low-entrepreneurial regions seem to experience a strong direct effect they are characterised by a large displacement effect, which lasts much longer compared with the highest $75 \%$ of regions in terms of start-up activity in Great Britain (Table 4; Fig. 6). Furthermore these regions have a very low-inductive effect, which is also much shorter in time. The results clearly indicate a negative net effect for low-entrepreneurial areas. Again, comparing log likelihood values from Tables 2 and 4, we can formally test whether the low-entrepreneurial areas differ from the other areas. The LR test statistics for the two cases identified above (see note 16) are now 30.8 and 26.0. This indicates that the differences are statistically significant at the $1 \%$-level.

\section{Implications}

This paper has examined whether it is possible to have "the wrong type of entrepreneurship" - defined as new firm formation that leads to zero or even negative subsequent employment.

In order to address this issue our paper uses a very similar approach to that of Fritsch and Mueller (2004) confirming their findings that the employment impact of new firm formation is in three discrete phases. The first and immediate impact is in terms of job creation, a second impact which is negative in terms of entrants displacing inefficient incumbent firms, and a third impact in terms of enhanced competitiveness. The full effects of this impact are felt over a decade.

Where the paper moves forward the work of Fritsch and Mueller is to emphasise that the impact on employment of new firm formation varies spatially within Great Britain. It shows both informally by presenting pictures and formally by applying statistical tests, that the employment impact is significantly greater in England - a country with high rates of new firm formation, than in Scotland which has significantly lower rates of new firm formation.

Its second striking finding is that when the lowenterprise counties (which are mostly but not exclusively located in the north of England and Scotland) as a group are compared with the rest of GB we find that the impact of new firm formation in these lowenterprise areas is overall negative. This means that the "wrong type of entrepreneurship" is indeed possible since raising the rates of new firm formation-presumably by public policy measures-would lead to reduced employment. 
Table 4 Long-term effects of new firm formation activity on employment change-low-entrepreneurial areas

\begin{tabular}{|c|c|c|c|c|}
\hline & \multicolumn{4}{|c|}{ 2-Year regional employment change $(\%)$} \\
\hline & \multicolumn{2}{|c|}{ Fixed effects estimator } & \multicolumn{2}{|c|}{ OLS estimator (Huber White) } \\
\hline & Un-restricted & Third-order polynomial & Un-restricted & Third-order polynomial \\
\hline \multicolumn{5}{|l|}{ Control group ( $>25$ percentile) } \\
\hline Start-up rate $(t)$ & $0.751 * *(3.02)$ & 0.718 & $0.537 * *(2.93)$ & 0.540 \\
\hline Start-up rate $(t-1)$ & $-0.521(1.72)$ & -0.211 & $-0.551 * *(2.87)$ & -0.298 \\
\hline Start-up rate $(t-2)$ & $0.105(0.35)$ & -0.524 & $0.005(0.03)$ & -0.547 \\
\hline Start-up rate $(t-3)$ & $-0.710 *(2.36)$ & -0.412 & $-0.665^{* *}(2.61)$ & -0.397 \\
\hline Start-up rate $(t-4)$ & $-0.432(1.42)$ & -0.066 & $-0.383(1.69)$ & -0.038 \\
\hline Start-up rate $(t-5)$ & $0.798 * *(2.58)$ & 0.321 & $0.799 * *(2.75)$ & 0.340 \\
\hline Start-up rate $(t-6)$ & $0.590 *(1.89)$ & 0.560 & $0.568 *(1.84)$ & 0.547 \\
\hline Start-up rate $(t-7)$ & $0.054(0.18)$ & 0.459 & $0.006(0.02)$ & 0.395 \\
\hline Start-up rate $(t-8)$ & $0.086(0.41)$ & -0.174 & $-0.086(0.41)$ & -0.308 \\
\hline \multicolumn{5}{|c|}{ Low-entrepreneurial areas ( $\leq 25$ percentile $)$} \\
\hline Start-up rate $(t)$ & $1.354 * *(2.72)$ & 1.452 & $1.756^{* *}(5.06)$ & 1.557 \\
\hline Start-up rate $(t-1)$ & $-0.117(0.18)$ & -0.295 & $-0.233(0.39)$ & -0.064 \\
\hline Start-up rate $(t-2)$ & $-0.429(0.71)$ & -0.895 & $-0.483(1.12)$ & -0.774 \\
\hline Start-up rate $(t-3)$ & $-1.856^{* *}(3.10)$ & -0.901 & $-1.749 * *(4.11)$ & -0.825 \\
\hline Start-up rate $(t-4)$ & $0.272(0.46)$ & -0.505 & $0.538(0.84)$ & -0.472 \\
\hline Start-up rate $(t-5)$ & $-0.420(0.71)$ & 0.011 & $-0.415(0.84)$ & 0.034 \\
\hline Start-up rate $(t-6)$ & $0.943(1.67)$ & 0.365 & $0.975(1.83)$ & 0.438 \\
\hline Start-up rate $(t-7)$ & $-0.436(0.76)$ & 0.275 & $-0.530(0.93)$ & 0.488 \\
\hline Start-up rate $(t-8)$ & $-0.163(0.37)$ & -0.541 & $0.493(1.62)$ & -0.068 \\
\hline Population density & $0.010(0.97)$ & $0.011(1.04)$ & $-0.001 * *(4.43)$ & $-0.001 * *(4.60)$ \\
\hline Hourly wages (constant prices) & $1.003 *(2.36)$ & $0.958 *(2.27)$ & $0.566^{* *}(3.72)$ & $0.573^{* *}(3.90)$ \\
\hline 2-Year employment change $(t-2)$ & $-0.350 * *(9.75)$ & $-0.343 * *(9.93)$ & $-0.266^{* *}(6.04)$ & $-0.264 * *(6.23)$ \\
\hline Spatial autocorrelation & $0.558 * *(7.96)$ & $0.533^{* *}(7.64)$ & $0.510 * *(5.42)$ & $0.496^{* *}(5.47)$ \\
\hline Constant & $-14.173 *(2.13)$ & $-13.633 *(2.05)$ & $-3.659 * *(2.92)$ & $-3.569 * *(2.85)$ \\
\hline$R^{2}$-adjusted & 0.3135 & 0.3096 & 0.3274 & 0.3247 \\
\hline F-value & 19.54 & 34.46 & 33.28 & 38.27 \\
\hline Log-likelihood & $-2,044.38$ & $-2,052.10$ & $-2,088.14$ & $-2,094.80$ \\
\hline Observations & 767 & 767 & 767 & 767 \\
\hline
\end{tabular}

* Significant at 5\%-level

** Significant at $1 \%$-level

$t$-values in parentheses

These results have serious implications for policy makers who, we have noted throughout this paper, have sought to raise new firm formation rates in the expectation that this would lead subsequently to employment creation.

Our first finding is that in some locations increases in new firm formation do indeed lead subsequently to new employment, but in other cases they do not. Our second result is that the impact on employment is greatest in the prosperous areas and least in the least prosperous areas. This implies that national enterprise policies risk being regionally regressive.

Our second result might be acceptable if it could be shown that in all areas the employment impact was positive, but this is not the case. We show that, for regions in the lower 25 percentile of Great Britain in terms of average start-up rate, new firm formation is associated with reduced 


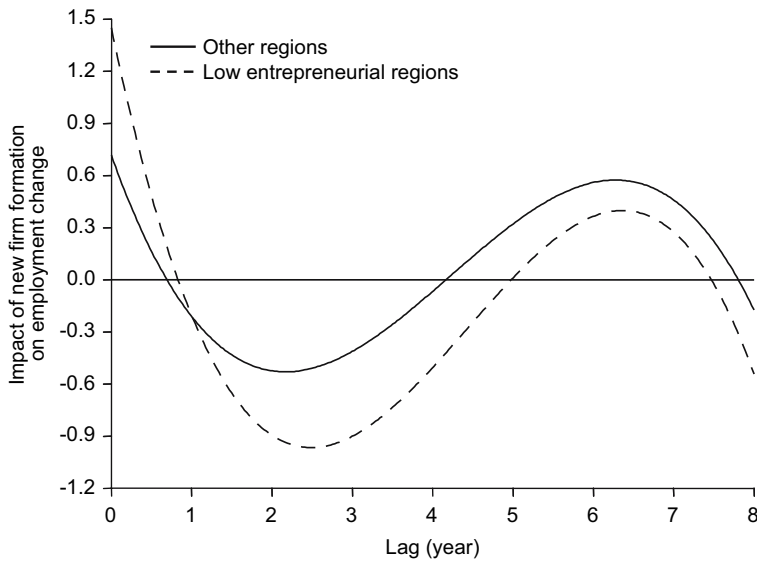

Fig. 6 Impact of new firm formation on employment change in low-entrepreneurial areas

employment. Eight of nine Scottish regions in our database belong to these 'low enterprise' regions, hence it is questionable whether the expenditure of $£ 140 \mathrm{~m}$ of taxpayers' funds over 9 years in Scotland has been productive. As we outlined in Sect. 2, we attribute the negative effect in lowenterprise regions to the firms in these locations being started by individuals with few employment options, low-personal skills and poor market prospects, but incentivised by the availability of public money being made available to those wishing to be enterprising.

\section{References}

Anselin, L. (1988). Spatial econometrics: Methods and models. Dordrecht: Kluwer Academic Publishers.
Anyadike-Danes, M., Hart, M., \& O'Reilly, M. (2005). Watch that space! The county Hierarchy in firm births and deaths in the UK, 1980-1999. Small Business Economics, 25(3), 273-292.

Disney, R., Haskel, J., \& Heden, Y. (2003). Restructuring and productivity growth in UK manufacturing. Economic Journal, 113(489), 666-694.

Fraser of Allander Institute (2001). Promoting business start ups: A new strategic formula. Glasgow, UK: University of Strathclyde.

Fritsch, M., \& Mueller, P. (2004). The effects of new business formation on regional development over time. Regional Studies, 38(8), 961-976.

Granger, C. (1969). Investigating causal relations by econometric models and cross-spectral methods. Econometrica, 37, 424-438.

Greene, F., Mole, K., \& Storey, D. (2004). Does more mean worse? Three decades of enterprise policy in the tees valley. Urban Studies, 41(7), 1207-1228.

Johnson, P. (2005). Targeting firm births and economic regeneration in a lagging region. Small Business Economics, 24(5), 451-464.

Keeble, D., Walker, S., \& Robson, M. (1993). New firm formation and small business growth in the United Kingdom: Spatial and temporal variations and determinants, Research Series, No. 15. Sheffield, UK: Employment Department.

Parker, S. (2004). The economics of self-employment and entrepreneurship. Cambridge: Cambridge University Press.

Small Business Service (2004). A government action plan for small businesses. London: Department of Trade and Industry.

van Stel, A., \& Storey, D. (2004). The link between firm births and Job creation: Is there a Upas tree effect? Regional Studies, 38(8), 893-910.

van Stel, A., \& Suddle, K. (2007). The impact of new firm formation on regional development in The Netherlands. Small Business Economics, DOI 10.1007/s11187-0079054-1, this issue.

Stewart, J. (1991). Econometrics. New York: Philip Allan. 